eastward velocity which it possessed when it left the equatorial regions. It is a matter of indifference in what way this energy is consumed by the molecules of the water, whether it be in friction in rotation, or whether it becomes potential in the raised water through which the current flows; for in either case it is the resistance offered by the stationary molecules which causes the moving molecules to lose their velocity. The resistance being molecular, that which holds true of eastward holds equally true of westward motion. This is proved also by the fact that a current flowing from a higher to a lower latitude has its westerly motion due to rotation as effectually checked and diminished as a current flowing from a lower to a bigher latitude has of easterly. And what holds true of motion to the east or to the west, holds equally true of motion to the south or north, for there is no reason why the resistance should be less in one direction than in another.

It therefore follows that it is impossible that 6 foot-pounds could impel a pound of water from the Equator to latitude $60^{\circ}$ against the molecular resistances to its motion, when during the passage of the pound of water it requires 9,000 foot-pounds to overcome the resistance to the easterly deflections which take place. Or if the molecular resistance of water be so infinitesimal that 6 foot-pounds is sufficient, then it is impossible that molecular resistance could consume 9,000 foot-pounds during the easterly deflection which takes place.

I respectfully submit that this is a clear and obvious demonstration of the mechanical impossibility of the gravitation theory of oceanic circulation.

Prof. Everett says that Mr. Ferrel's argument from the tides is quite conclusive in showing that the forces arising from difference of temperature are of sufficient magnitude to keep up an oceanic circulation. If. Prof. Everett, like Mr. Ferrel, really supposes that a slope produced by the moon is the same as one produced by difference of density, and that the process by which the water tends to regain its level is the same in both cases, I am not surprised he should consider Mr. Ferrel's argument conclusive.

I beg to refer Mr. Wallace to the Philosophical Magazine for October i871, p. 244, for an explanation of the fallacy of Dr. Carpenter's famous experiment to which he alludes.

Had the present state of my health permitted, I should have entered somewhat more fully into some of the above points, but in the meantime I must withdraw from any further discussion.

Edinburgh, August 27 JAMES CROLL

\section{The Aurora of Feb. 4}

THE Ifon. Rawson Rawson, Governor of Barbadoes, has favoured us with the following note :-

"Memo, for his Excellency the Governor-in-Chief.

"The aurora of the 4 th of February last, to which you allude, and notices of which you kindly sent me in NATURE, was seen here, and caused much concern.

"I was not myself an eye-witness, but I have descriptions of it from trustworthy persons. I was first informed of it by a servant of mine, who has the overlook of Mont Grace. * He was returning to his home near the Fort after 7 P.M., when, about a mile away from Mont Grace, his attention was arrested by what he imagined was a 'great fire'-the trees at Mont Grace and all about the yard were lighted up and clearly seen. My brother, who leased a sugar plantation in the neighbourhood of Government House, and Mr. Gordon, who owns one in that immediate neighbourhood, happened to be both in Scarborough at the time, and, seeing the 'great glare,' were both seized with the notion that their respective properties were on fire, and hastened out to them to find that the supposed fire was farther away.

"Mr. Taylor, master of the barque Tobago, was riding at anchor at Courland Bay, + and was a witness of this aurora. $\mathrm{He}$ described it to me as of ' a dark-red colour, extending half way up to the zenith, and very brilliant, its situation being about N.W. by W.' 'The labourers exclaimed that St. Vincent was on fire.

"This aurora lasted till half-past nine. Such a phenomenon, if not altogether unknown in this latitnde, is at any rate very rare.

"Tobago."

"Dugald Yeates"

* Mr. Yeates' property, three miles from Scarborough, Island of Tobago (Tobago is in $x x^{\circ} 9^{\prime} \mathrm{N}$. lat., and $60^{\circ} 12^{\prime}$ W. long.)

$t$ On the opposite side of the island, $i . c$., the northern side.

\section{The Solar Spectrum}

I HAVE lately obtained and read "Schellen's Spectrum Analysis," translated by the Misses Lassell, and edited by Mr. Huggins, and feel at length constrained to dissent from a statement which $I$ there find-in this the present standard work on the subject-distinctly and repeatedly made, as I have seen it made elsewhere kefore, a statement belief in which has tended and must always tend to deter many from prosecuting independently a most interesting study. I refer to the passage beginning "The Possibility of Observing" (p. 382) to end of paragraph, italicising the words "ordinary" in 1.7 of p. 383 " by increasing the number of prisms" three lines below, "highly dispersive power" in line 22.] The italics are mine, and are intended to indicate that to which I object, not that the particular passages in which they occur are explicitly incorrect, but that they implicitly convey the incorrect notion, that the "highly dispersive power" is essential to the primary success of the observation "of the lines of the prominences in bright sunshine."

The reason of my objection will be found in the following ex. tract from an unpublished letter dated May 3, 1869:-

"I think it will surprise you to hear that I have just seen Mr. Lockyer's three bright solar lines at several parts of the sun's circumference with the Royal Society's telescope and spectroscope ivithout any appliances or devices whatsoever (sic), and that with the greatest ease and certainty. Had I merely looked for them, or for anything of the kind, a twelvemonth ago, I do not see how I could have failed to see them!

"When the slit is placed parallel to the limb, the red line is vivid across a bright solar spectrum, and the line near $D$ (there is no doubt about its position when seen in connection with the solar spectrum) which is less prominent, as also the line at or near F, are easily seen."

Also in another letter of the same date:- "Before I went into camp last December (while still rumours only of Janssen's observations were current) I resolved to try with coloured glasses. They were not received till too late; the instrument was packed up, and I was away. By the time I returned the question had passed on ; but I still wished to carry out original intentions, and prepared accordingly, and was proceeding to direct the telescope this morning when I saw the red line in the undefended part of the slit, where I was focussing on the sun's limb. Of course, I saw at once that I could do without my coloured glass, which, practically, limited my field of view, and accordingly removed it, and examined various parts of the limb with no screen at all. At nearly all I could see the same three lines. At one place the red was so bright that an outsider looking in at the spectrum would certainly have carried away the impression of a coloured ribbon with a bright line of red near the end." As a matter of fact biy wife had no difficulty in seeing at any rate the red line.

Now, the application of this is to be found in the fact that the spectroscope in question contained a single equilateral prism and no more.

Were there any merit in a fortuitous discovery of the kind, it would suffice for me to declare that I was in complete ignorance of the methods and appliances by which MM. Janssen and Lockyer had succeeded in doing long before that which I now found so obvious. What $I$ do insist upon is that the visibility not of the prominence lines only (see also Proc. R.S., No. 113, $\mathrm{I} 869$, in this connection), but of the prominences themselves does not require a high dispersion. I have a fair acquaintance with prominence forms; but it has been derivedi almost entirely from a study of them with an open slit, the use of which I had learnt long before, and a single prism spectroscope.

Of course, I do not contest that the power of extended examination depends directly upon increase of dispersive power, only that the lozver limit is fully attained by a single $60^{\circ}$ prism.

That high telescopic power is not essential either is proved by the fact that $I$ have examined prominences by applying a $I_{\frac{3}{x}}^{3}$ in. object glass to the end of the sliding tube of the spectroscope at solar-focal distance, and using the instrument on its "soirée" stand on a table-by way of experiment-with an amount of success which, in 1868 , would have made some sensation.

It is obvious to remark in reply that probably the explanation of the ready visibility asserted is to be found in more favourable climatic conditions. I cannot admit it. By night, it is true, there is often a remarkable translucency; but the dusty, agitated state of the atmosphere (in May) under a tropical sun, and at an inland station, can certainly not be considered favourable for cbservations of this particular character. And even were such 